\title{
STUDY THE EFFECTS OF CARBON NANO TUBES ON CORROSION BEHAVIOR OF NI-PELECTRO-LESS COATINGOF LOW ALLOY STEELS IN SALT WATER
}

\author{
ABDUL RAHEEM K. ABIDALI ${ }^{1}$ \& ALAA MOHAMMED HUSSEIN WAIS ${ }^{2}$ \\ ${ }^{1}$ University of Babylon, Iraq \\ ${ }^{2}$ Al-Mustaqbal University College, Iraq
}

\begin{abstract}
The basic aim is to study the resistance of corrosion and hardness of heat treatment of coatings with electro-less NiP-CNT. Various concentration of CNTs ranging, $0,0.1,0.2$ and $0.4 \mathrm{~g} / \mathrm{L}$ in Ni-P-CNT composite was deposited on low alloy steel in electro-less immersion. The Ni-P-CNT electro-less coatings were prepared by using nickel chloride as a source for nickel in the alkaline bath and used CNT. The formulas were characterized with means of EDS, SEM, micro hardness, surface roughness and corrosion measurements. Results of the micro hardness show that hardness higher (560 HV) was achieved for sample (Ni-B-0.1g/l CNT) heat treated. Results enhance that the concentration of CNTs caused the structure of as-coated Ni-P conversion from amorphous to crystalline. Compared to the Ni-P coating, the resistance of corrosion of composite coating (Ni-P-CNT) are better, and they become much better with the increase of the CNT concentration. The addition of CNT makes the coating denser, and the presence of CNT decreases the size of grain to the heat treated formulas but too much CNT deposited on the substrate leads to a high region of the CNT wrapped together and the resulting agglomeration that occur is very unfavorable to coating, resulting in the lead resistance of the corrosion of the composite coating which becomes worse

KEYWORDS: Electro-Less Ni-P-CNT Coating, Micro hardness \& Corrosion Resistance
\end{abstract}

Received: Jul 06, 2019; Accepted: Jul 26, 2019; Published: Sep 03, 2019; Paper Id.: IJMPERDOCT201913

\section{INTRODUCTION}

The recent years electrical and electronics engineering have faced the problem of how to coat the dielectrics (ceramics, polymers) and semiconductors. Certain metals are difficult to be coated such as titanium, aluminum, tungsten, molybdenum, and magnesium alloys [1].

Coating materials that resist corrosion is an effective way to protect against corrosion and wear. Coating layer must have a suitable thickness to make them able to isolate all the reactants from each other. There are different types of coating, including metallic plating, which includes electroplating and electro less coating. The known way is the immersion in molten metal and the method of spraying minerals in addition to non-metallic plating [2].

The electroplating is defined as the deposition of the product layer on a surface of the metal. That treatment is worked with the technique of an electrolytic, which contains electrolyte solution for metal liquefy salt required to be deposited. It contains of the electroplating cell an anode. In the surface of the anodic, process of the oxidation occurs. In cathode, reduction of the cathode surface of the positive ions occurs which represents the electrolyte of the conducting medium. Movement of electric current through the electrolyte is related with the flow of material. Also, a salt which enables conductivity of the solution [3]. 
Plating electro-less of Ni-P alloy technique is a well-known commercial treatment and has applications in several fields because it has very good properties such as large corrosion resistance, large wear resistance, large hardness and excellent ductility. Electro-less coating is a technique of coating metal by chemical rather than by electrical means. It is beneficial because it allows the coating of metals and plastics by a process of controlled auto catalytic, or self-continuing reduction. Chemical reaction reduction with the controlled chemical coating, the electro-less coating has developed as regions growth in metal finishing, surface engineering etc. and is probable to grow at a rate of beyond fifteen percent per annum, certainly, no other chemistry is growing in this rate. Electro-less Coatings has alone mechanical and physicochemical properties and is being used increasingly [4].

The advantages for this technique is regularity of the thickness of the coating layer even on parts with complex and small shapes, which is one of the main difficulties in electroplating due to weak ionic strength for electroplating, as coating layers are generally devoid of porosity which prevents the entry into force of ions and reduce the corrosion process. For these technical features as the microstructure of the layers of coating, change crystalline and deposited the chemical compounds by heat treatment to improve resistance to corrosive environments [5].

Improved mechanical properties, resistance of wear and resistance of corrosion, and coatings of nano composite have large attention. Nano composite coating has another appropriate identified solid lubricants likeMoS2 [9], PTFE [10] and CNT [11] which can act to decrement the friction coefficient, also enhances the wear resistance on the surface. Because of a great tensile strength of carbon nano tubes with elastic modulus [13], makes it widely used in ceramic composites and metallic composites such Cu-CNT [14], ZrO2-CNT [15]. Treatments of mechanical process of chemical treatment, including used surfactants of the CNT and ball-milling are the more general processes used to treatment their bad dispersion issue $[16,17]$.

The aim of this study is to explain the effects of the behavior of electro-less Ni-B-CNT coating with various concentrations of CNT, and heat treatment coating on some mechanical properties (micro hardness and roughness), resistance of corrosion and microstructure of low alloy steel.

\section{EXPERIMENTATION}

\section{Preparation of Substrate}

Substrate metal used in this work was low alloy steel specimens (20 mm diameter $\times 10 \mathrm{~mm}$ height $)$ as the substrates. The chemical analysis for this alloy and it's detail composition (weight \%) is shown in Table 1.

Table 1: Chemical Compositions of Low Alloy Steel

\begin{tabular}{|l|c|c|c|c|c|}
\hline Element & $\mathbf{C}$ & $\mathbf{S i}$ & $\mathbf{M n}$ & $\mathbf{A l}$ & $\mathbf{C u}$ \\
\hline $\mathrm{W} \%$ & 0.311 & 1.12 & 1.17 & 0.0084 & 0.076 \\
\hline
\end{tabular}

All specimens were grinded and polished as ASTM by emery paper (tungsten oxide paper) No. (180-2000) after which the samples were washed by distilled water and ethanol, and dried by using an electrical dryer. Polishing was conducted by diamond paste, Specimens were immersed in acetone for $30 \mathrm{~min}$. Before coating specimens were immersed in a solution including materials such as $30 \mathrm{~g} / \mathrm{L} \mathrm{NaOH}, 60 \mathrm{~g} / \mathrm{L} \mathrm{NaCO} 3$ and $60 \mathrm{~g} / \mathrm{L} \mathrm{NaPbo} 4$ for one minute at $60^{\circ} \mathrm{C}$ by moving the electrolyte using magnetic stirring by supplying power(5 volt). This is done to remove oil and any dust om metal surface after which the specimens were washed with distilled water, and is directed to be immersed in coating solution. 


\section{CNT Ball-Milling}

MWCNT with purity more than 95\%, 10-30 $\mu \mathrm{m}$ with length, 5-10nm inside diameter and 20-30 nm with outside diameter. To enhance dispersion for CNT in electro-less coating bath, as-received CNT were ball milled at (3 hours )using by machine of planetary ball-mill with balls of steel with various diameters have been used for mix CNT in cylindrical stainless steel jar, rotating speed and then $(10 \mathrm{~min})$ fracture intermitting each $(20 \mathrm{~min})$ of milling to reduce heat build-up. Ethyl alcohol has been used in wet mixing.

In order to dispersed uniformly carbon nano-tubes in electro less Ni-B coatings and no agglomeration to provide stable and homogenous dispersion in the metallic matrix phase. Should use surfactants (sodium dodecyl sulfate (SDS) with CNT and together mixed with water by ultrasonic device for $45 \mathrm{~min}$.

\section{Electro Less Bath Preparation}

After completion of preparing surfaces for coating, electro less bath was prepared for the process according to concentrations shown in Table 2. The coating Ni-P was deposited on low alloy steel by the process of electro less plating. Value of PH in the plating bath was varied between $(8-10)$. The electro less plating of $\mathrm{Ni}-\mathrm{B}$ was perform at $\left(95 \pm 2^{\circ} \mathrm{C}\right)$ for $60 \mathrm{~min}$. Throughout the coating, solution of bath is agitate by a magnetic stir to avoid localized overheating and reduce the fluctuation of ionic concentration. The coating process, for Ni-P-CNT deposition by changing of concentration for CNT $(0$,

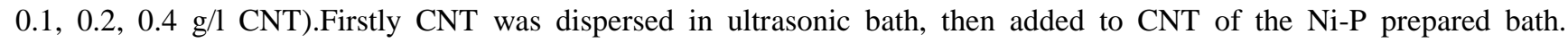
Figure1shows the experimental setup for the electro less composite deposition. After the completion of the process of coating, specimens were placed inside a vacuum oven, to dry for 30 minutes, at a temperature $50^{\circ} \mathrm{C}$.

Table 2: Operating Conditions for Electro Less Bath

\begin{tabular}{|l|c|}
\hline \multicolumn{1}{|c|}{ Bath Composition } & g/L \\
\hline Nickel chloride (NiCl2.6H2O) & 30 \\
\hline Sodium hypophosphite (NaH2Po2) & 10 \\
\hline Amina chloride & 50 \\
\hline Sodium citrate & 84 \\
\hline Sodium Dodecyl Sulfate (SDS) & 2 \\
\hline Carbon nanotube (CNT) & $0,0.1,0.2,0.4$ \\
\hline Operating conditions & \\
\hline pH & $(8-10)$ \\
\hline Temperature & $950 \mathrm{C}$ \\
\hline Time & $1 \mathrm{HR}$ \\
\hline
\end{tabular}

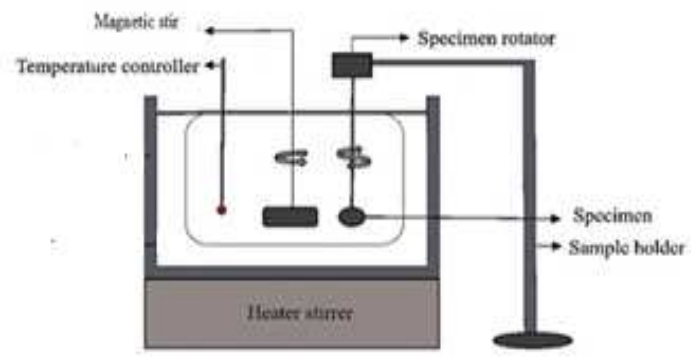

Figure 1: Setup of Experimental of Electro Less Deposition. 


\section{Heat Treatment}

In this work, annealing process is conducted in vacuum furnace in which coated specimens are soaked at a temperature $\left(400^{\circ} \mathrm{C}\right)$ for a period of $(1)$ hour. Then, specimens are furnace cooled at room temperature.

\section{Characterization}

Micro hardness of the coating layers were measured by using (TH-717 Vickers hardness tester), a load of $25 \mathrm{~g}$ was applied for $15 \mathrm{sec}$. Three readings were recorded for each specimen coated and one at the substrate. Then, the average value was taken. The value of measurement for surface roughness was completed for the coated samples before and after heat treatment using a common parameter Ra in $\mu \mathrm{m}$, surface roughness test (HER210 Model) was used to calculate Ra with accuracy $0.05 \mu \mathrm{m}$ and the mean of (10) measurements was recorded.

\section{RESULTS AND DISCUSSIONS}

Scanning Electronic Microscope (Sem)

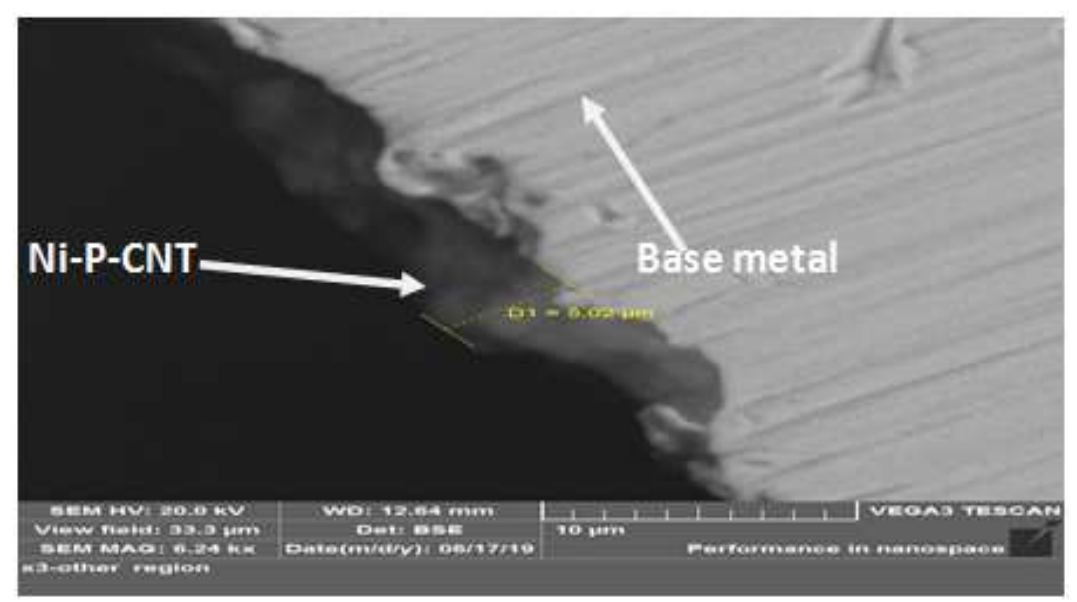

Figure 2: SEM of Ni-P-CNT Coating of Surface of Cross Section of Heat Treatment Specimens

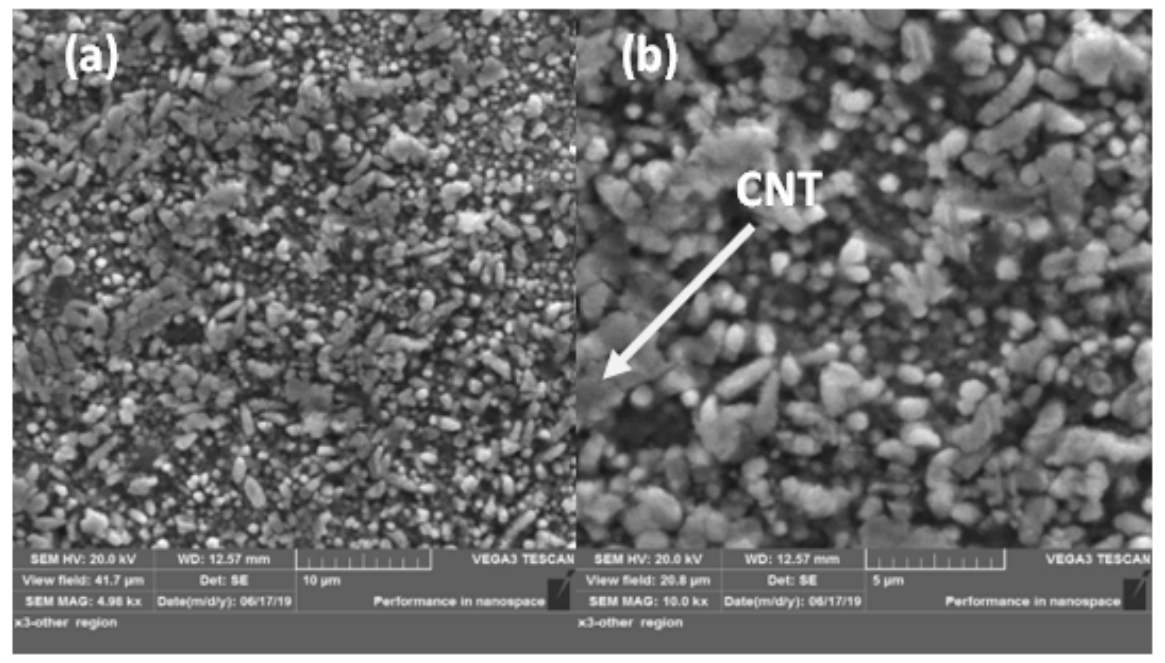

Figure 3: SEM of Ni-P-CNT at (A) (4980 X) Magnification and (B) (10000 X) Magnification. 
Figure 2express the cross sectional the surface coating Ni-B-0.1g/l CNT and thickness of coating $(5.02 \mu \mathrm{m})$. It was treated at $400{ }^{\circ} \mathrm{C}$ for 1 hour.

The SEM study that was performed on the agglomerates reveals that they are composed of particles. Figure 3 express the morphology of the CNT embedded in Ni-P matrix, the CNT precipitates, they are of irregular shapes. They act as reinforcement particles in Ni-P coatings. In addition, CNT appears in the coatings which contain CNT particles. The coatings composite express a structure of spherical nodular by good uniformity and dense coverage.

\section{EDS Characterization}

Figure 4 shown the EDS of Ni-P-CNT composite electro-less coatings at the required parameters of the process, that indicates the coating contains $80 \% \mathrm{Ni}, 10.5 \% \mathrm{P}$ and $0.1 \% \mathrm{CNT}$ (mass fraction), which gives exactly the initial amount of $10.5 \% \mathrm{P}$. when the percentage of $\mathrm{P}$ is higher at $10 \%$ the structure of the coating is expected to be amorphous. This is exactly what happened.

The indicates phosphorus content, that the coating is a type of coating with high phosphorus. This result is supported by the SEM metallographic, figure 3. high incorporation of CNT particles in composite coatings can be ascribed to the smaller size of the particles[18], is believed that these particles swept away from the electrode surface.

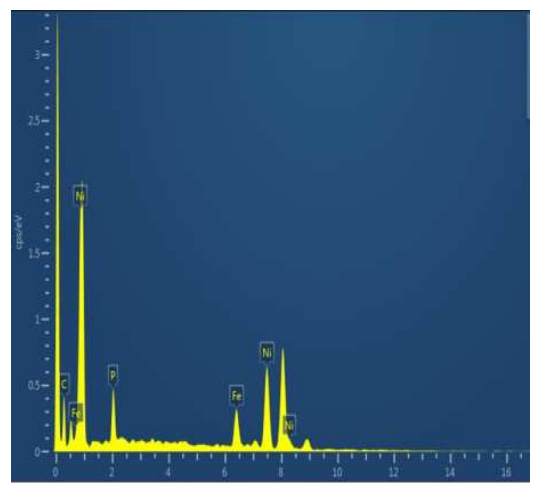

Figure 4: EDS Spectrum of Electro-Less Ni -P-CNT Coating.

\section{Surface Roughness}

Roughness of the substrate data was illustrated in Table 4, as-plated and annealed. As mentioned above increase of CNTs' concentration to $0.4 \mathrm{~g} / \mathrm{L}$ causes a significant rising in the roughness. The roughness of sample Ni-P-0.4g/L CNT was higher when compared with other specimens, because large concentration of CNT which may lead to product agglomeration.

Table 3: Result of Surface Roughness Samples

\begin{tabular}{|l|l|}
\hline \multicolumn{1}{|c|}{ Sample } & $\mathbf{R a}(\boldsymbol{\mu})$ \\
\hline Substrate & 0.3 \\
\hline Ni-Pa plated & 0.1 \\
\hline Ni-P-0.1 g/L CNT a plated & 0.17 \\
\hline Ni-P-0.2 g/L CNT a plated & 0.25 \\
\hline Ni-P-0.4 g/L CNT a plated & 0.3 \\
\hline Ni-P a annealed & 0.15 \\
\hline Ni-P-0.1 g/L CNT a annealed & 0.2 \\
\hline Ni-P-0.2 g/L CNT a annealed & 0.3 \\
\hline Ni-P-0.4 g/L CNT a annealed & 0.4 \\
\hline
\end{tabular}




\section{Micro Hardness}

Figure 5 shows the surface of samples micro hardness due to heat treatments noted, the CNTs reinforcing ability have forced in enhancing the micro hardness of the surface, particularly in the sample of Ni-P-0.1g/L CNT, these can be related with reinforcement and uniform distribution of carbon nano tubes about these specimen. The hardness of Ni-P-0.2g/L CNT and Ni-P-0.4g/L CNT was less in comparison with the specimen having $0.1 \mathrm{~g} / \mathrm{L} \mathrm{CNT}$ due to the large CNTs concentration, in addition to that, segregation that happened at the composite led to a decrease in the composite micro hardness of coated layer [19]. However, the hardness of the heat treated coatings of Ni-P was significantly increased. For example, it was about 2.8 times with respect to the corresponding value of the uncoated steel. However, the coating itself is an effective technique to achieve this goal whether, using Ni-P only or incorporating with CNT particle. However, the reasons behind such an increase in hardness appears to be different before and after heat treatment. P. Gadhari, et al. (2014) [20], pointed out that, the micro hardness of annealed composite coatings depends on three factors, level of incorporation of particles, annealing temperature and uniform distribution with less agglomeration of particles. For instance, the enhancement of hardness of Ni-P coatings when the deposition process variables will remain, the nature of the coating layer only feature that defines the extent of protection that can be provided with the coating.

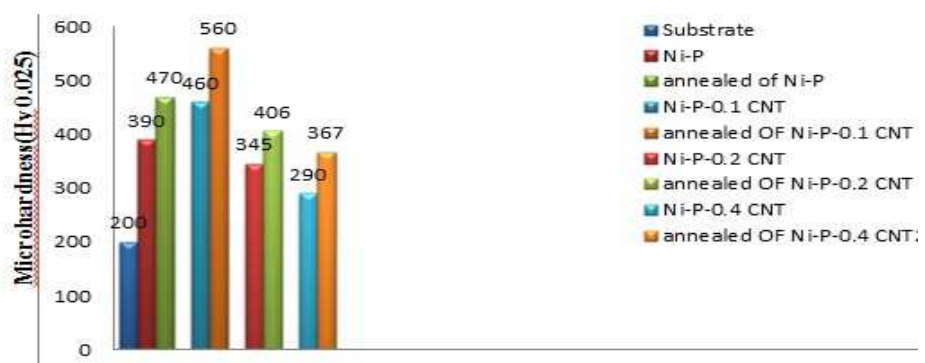

Figure 4: Micro Hardness Results of as-Plated and Heat Treatment of Samples Surface.

\section{Corrosion Behavior}

Corrosion behavior of the coatings was calculated with the technique of Tafel extrapolation. The results of test of electro chemical, Ecorr, Icorr. and corrosion rate coatings, are listed in Table (4).

Table 4: The Results of Electrochemical Test

\begin{tabular}{|l|c|c|c|}
\hline \multicolumn{1}{|c|}{ Sample } & $\begin{array}{c}\text { Ecorr. } \\
(\mathbf{m} \mathbf{r} /\end{array}$ & Icorr. $(\boldsymbol{\mu A})$ & $\begin{array}{c}\text { Corrosion Rate } \\
(\mathbf{m p y})\end{array}$ \\
\hline Substrate & -576 & 64.18 & 12.3 \\
\hline (Ni-P)a plated & -573 & 39.89 & 7.4 \\
\hline $\begin{array}{l}\text { (Ni-P-0.1 g/l CNT) a } \\
\text { plated }\end{array}$ & -179.5 & 8.39 & 6.2 \\
\hline $\begin{array}{l}\text { (Ni-P-0.2 g/l CNT) a } \\
\text { plated }\end{array}$ & -682 & 33.54 & 37 \\
\hline $\begin{array}{l}\text { (Ni-P-0.4 g/l CNT) a } \\
\text { plated }\end{array}$ & -563 & 199 & 4.6 \\
\hline (Ni-P) a annealed & -400 & 25 & 0.025 \\
\hline $\begin{array}{l}\text { (Ni-P-0.1 g/l CNT) a } \\
\text { annealed }\end{array}$ & -162.1 & 0.154 & 5.5 \\
\hline $\begin{array}{l}\text { (Ni-P-0.2 g/l CNT) a } \\
\text { annealed }\end{array}$ & -343 & 30 & 27 \\
\hline $\begin{array}{l}\text { (Ni-P-0.4 g/l CNT) a } \\
\text { annealed }\end{array}$ & -391 & 150 & \\
\hline
\end{tabular}


Coating in enhancement of properties of the corrosion is due to thickness of electro less deposition is so uniform and the aptitude of coatings Ni-P ability as barrier effective between environment of corrosion and metal, in Figure 5 shows before and after heat treatment. However, increase in thickness leads to a decrease of porosity, porosity is greatly reduced as increase \% $\mathrm{P}$ is larger than 10\% [21]. Thickness of electro less deposition is so uniform and has low value of porosity. High phosphorus content (10-13) \% P has given better corrosion resistance. The average content in this work was $12 \% \mathrm{P}[22,23]$ pointed out that at such value the structure of the coating layer is amorphous. Hence, there is no grain boundaries which act as corrosion sites for initiation. Such non-crystalline coating layer form glassy, passive protective layer. However, the addition of CNT particle was really innovative. It produced a great reduction in corrosion current, $0.025 \mu \mathrm{A}$. at Ni-P-0.1g/l CNT after heat treatment $\left(\left(400^{\circ} \mathrm{C}\right)\right.$ for a period of $(1)$ hour $)$. This improvement is attributed to base causes of the behavior where the carbon nano tubes filled in the holes of every micro on surface through process of the deposition of electro less coating.
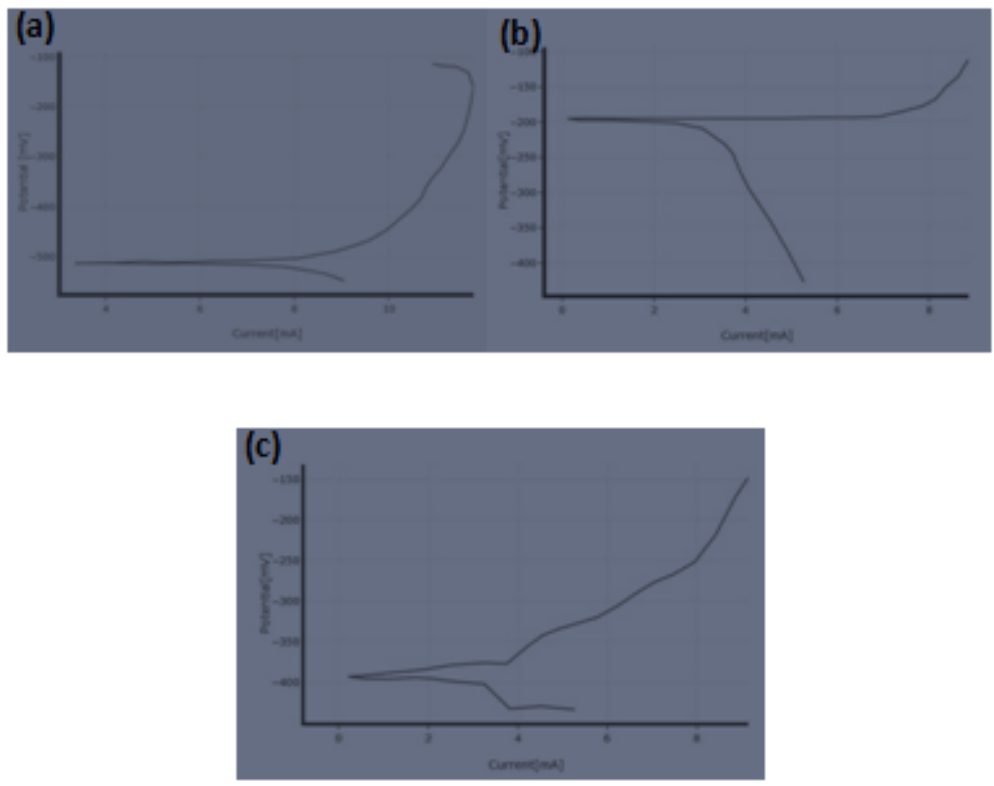

Figure 9: Polarization of Tafel Curves of The (A) as-Substrate,(B)Ni-P-0.1g/L CNT(Before Heat Treatment), (C) Ni-P-0.1g/L CNT(After Heat Treatment).

\section{CONCLUSIONS}

- Coating low carbon steel with Ni-P, the micro hardness increased from (200 HV) to (470 HV) after heat treatment.

- Incorporation of both CNT particles in Ni-P coating layers increased micro hardness (Ni-B-0.1 CNT) to (460 HV) and $(560 \mathrm{HV})$ after heat treatment.

- After heat treatment however, the weight lost was almost (zero) through wear test.

- Coating layer of Ni-P-0.1g/l CNT reduced the corrosion current after the heat treatment from $(8.39 \mu \mathrm{A})$ to $(0.154 \mu \mathrm{A})$.

- No flaws were observed in the coating layers after heat treatment. 


\section{REFERENCES}

1. M. Petrova, Z. Noncheva and E. Dobreva, "Electro less Deposition of Nano composite NIP-Coatings on Metal Substrates", 51st Internationals Wissen schaftliches Kolloquium, Vol. 1, September 2006.

2. D. Baddly and J. Cannon, "Progressive Engineering Materials", Hodder and Stoughton, Vol. 1, 1988.

3. F. Lowenheim, "Guide to the Selection and use of Electroplated and Related Finishing", American Society for Testing and Materials, ASTM Publication, Vol. 1, 1982.

4. R. Agarwala and V. Agarwala, "Electro less Alloy/Composite Coatings: A Review", Sadhana, Vol. 28, pp. 475-493, June 2003.

5. Reddy, B. M., Reddy, Y. V., \& Reddy, B. C. M. Impact Strength, Water Absorption and Chemical Resistance of Untreated and Treated Cordia Dichotoma Fiber/Polyester Composite.

6. N. Lin, H. Zhang, J. Zou, P. Han, Y. Ma and B. Tang, "Improvements in Wear and Corrosion Resistance of RB400 Anchor Rod Steel by Electroless Ni-P Plating", International Journal of Electrochemical Science, Vol. 10, pp. 357, November 2015.

7. O. R. Monteiro, S. Murugesan, V. Khabashesku, Electroplated Ni-B films and Ni-B metal matrix diamond nano composite coatings, Surf. Coat. Technol. 272 (2015) 291-297.

8. V. Niksefat, M. Ghorbani, Mechanical and Electrochemical Properties of Ultrasonic-Assisted Electroless Deposition of Ni-BTiO2 Composite Coatings, J. Alloy. Compd.633 (2015) 127-136

9. Akwanya, A. N. The Interpreted World's Resistance to Perishing in Wole Soyinka's Aké.

10. P. Wu, H. Du, X. Chen, Z. Li, H. Bai, E. Jiang, Influence of WC particle behavior on the wear resistance properties of Ni-WC composite coatings, Wear 257 (2004) 142-147.

11. Y. He, S. Wang, F. Walsh, Y.-L. Chiu, P. Reed, Self-lubricating Ni-P-MoS2 composite coatings, Surf. Coat. Technol. 307 (2016) 926-934.

12. Y. Wan, Y. Yu, L. Cao, M. Zhang, J. Gao, C. Qi, Corrosion and tribological performance of PTFE-coated electro less nickel boron coatings, Surf. Coat. Technol. 307 (2016) 316-323.

13. C. Carpenter, P. Shipway, Y. Zhu, Electro deposition of nickel-carbon nano tube nano composite coatings for enhanced wear resistance, Wear 271 (2011) 2100-2105.

14. AP Damodaran, S. (2019). Resistance to Power as Depicted in the Hacker Wars. IMPACT: International Journal of Research in Humanities, Arts and Literature (IMPACT: IJRHAL) ISSN (P), 2347-4564.

15. G. Hatipoglu, M. Kartal, M. Uysal, T. Cetinkaya, H. Akbulut, The effect of sliding speed on the wear behavior of pulse electro Co-deposited Ni/MWCNT nano composite coatings, Tribol. Int. 98 (2016) 59-73.

16. M.-F. Yu, O. Lourie, M. J. Dyer, K. Moloni, T. F. Kelly, R. S. Ruoff, Strength and breaking mechanism of multiwalled carbon nanotubes under tensile load, Science 287 (2000) 637-640.

17. Khedr, A., Elmonir, W., \& Sobeih, A. (2016). Public health risk of Listeria Monocytogenes in raw milk in Egypt: virulence genes, antibiotic-resistance and high-risk consumption practices. Inter J Appl Nat Sci, 5, 57-64.

18. P.-C. Tsai, Y.-R. Jeng, J.-T. Lee, I. Stachiv, P. Sittner, Effects of carbon nano tube reinforcement and grain size refinement mechanical properties and wear behaviors of carbon nano tube/copper composites, Diam. Relat. Mater. 74 (2017) 197-204.

19. V. Puchy, P. Hvizdos, J. Dusza, F. Kovac, F. Inam, M. Reece, Wear resistance of Al2O3-CNT ceramic nano composites at room and high temperatures, Ceram. Int. 39 (2013) 5821-5826. 
20. B. Munkhbayar, M. J. Nine, J. Jeoun, M. Bat-Erdene, H. Chung, H. Jeong, Influence of dry and wet ball milling on dispersion characteristics of the multi-walled carbon nano tubes in aqueous solution with and without surfactant, Powder Technol. 234 (2013) $132-140$

21. S. Allahkaram, A. Zarebidaki and T. Rabizadeh, "Evaluation of Electroless Ni-P and Ni-P Nano-Composite Coatings Properties", UFGNSM, Vol. 5, pp. 817-824, 2012.

22. J. Umeda, B. Fugetsu, E. Nishida, H. Miyaji, K. Kondoh, Friction behavior of network-structured CNT coating on pure titanium plate, Appl. Surf. Sci. 357 (2015) 721-727

23. P. Gadhari and P. Sahoo, "Study of Tribological Properties of Electro less Ni-P-Al2O3 Composite Coatings", IOSR Journal of Mechanical and Civil Engineering, Vol. 1, pp. 34-37, 2014.

24. R. Parkinson, "Properties and Applications of Electro less Nickel", Nickel Development Institute, Vol. 1, 1997.

25. O. Khalifa and E. Sakr, "Electro less Nickel-Phosphorus-Polymer Composite Coatings", The Open Corrosion Journal, Vol. 2 , pp. 211-215, 2009.

26. G. Yin-ning, H. Wei-jiu, Z. Rong-chang and Z. Yi, "Influence of pH Values on Electro less Ni-P-SIC Plating on AZ91D Magnesium Alloy", Transactions of Nonferrous Metals Society of China, Vol. 20, pp. 674-678, January 2010.

\section{AUTHORS PROFILE}

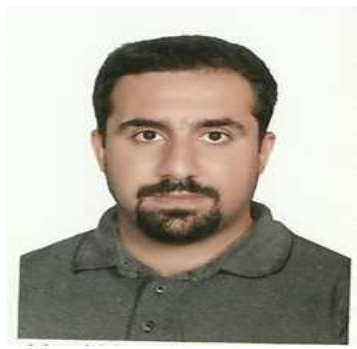

Iam(Alaa Mohammed Hussein Wais)born in Hilla 1979and received BSC in material engineering in Babylon university in 2002.I complete M.Sc.in material engineering in the field of Effect Of Friction Stir Processing On Mechanical Properties of The Cast Aluminum-Silicon Alloysin 2013.I studies Tribological behaviour of plasma nitride nano composite coating of Ni-B-Carbon nanotubes in PhD project in 2019(Date of discussion PhD project) .I had more 8 papers .Now more attention in the surface engineering field to enhance surface properties against wear and corrosion effects.I am studying in Al-Mustaqbal University College, Babylon, Iraq since 2014.

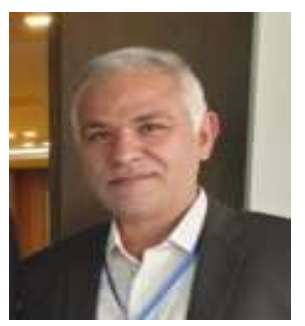

(Abdul Raheem K.AbidAli ) born in Hilla 1975and received BSC in material engineering in Babylon university in 1997.I complete M.Sc.in material engineering in the field of stress analysis of laminated composite by finite element analysis in 2000.I studies the martensitic transformation and mechanical behavior of copper based shape memory alloy in PhD project in 2007.I had more 45 papers since 2008 in the $\mathrm{Ni}$ Ti shape memory alloy and in the field composite of material. Now more attention in the surface engineering field to enhance surface properties against wear and corrosion effects. 
